\title{
PERBEDAAN PERSEPSI MAHASISWA MENGENAI KOMPETENSI DOSEN TERSERTIFIKASI (Studi Pada Mahasiswa Prodi Pendidikan Akuntansi IKIP PGRI MADIUN)
}

\author{
Elva Nuraina \\ Nik Amah \\ IKIP PGRI MADIUN \\ sigmaku87@gmail.com
}

\begin{abstract}
This study aims to determine the differences in students' perceptions regarding the competence of certified lecturer. The study was conducted on students of Accounting Education department IKIP PGRI MADIUN with samples of 80 students. Sampling technique done by proportional random sampling. Determination of the number of samples generated using a quota sample and 80 students. Data was collected through a questionnaire instrument, while the data analysis done by one way analysis of variance (one way ANOVA). The results showed that there were no differences perceptions of student in class 2010, 2011, 2012, and 2013 with regard to certified lecturer competence.
\end{abstract}

Key words: student perception, competence, certified lecturer.

\begin{abstract}
Abstrak: Penelitian ini bertujuan untuk mengetahui perbedaan persepsi mahasiswa mengenai kompetensi dosen tersertifikasi. Penelitian dilaksanakan pada mahasiswa Program Studi Pendidikan Akuntansi IKIP PGRI MADIUN dengan jumlah sampel 80 mahasiswa. Teknik pengambilan sampel dilakukan dengan teknik proportional random sampling. Pengumpulan data dilakukan dengan instrumen berupa kuesioner, sedangkan analisis data dilakukan dengan analisis varian satu jalan (one way ANOVA). Hasil penelitian menunjukkan bahwa tidak terdapat perbedaan persepsi mahasiswa tahun angkatan 2010, 2011, 2012, dan 2013 mengenai kompetensi dosen tersertifikasi pada Program Studi Pendidikan Akuntansi IKIP PGRI MADIUN.
\end{abstract}

Kata kunci: persepsi mahasiswa, kompetensi, dosen tersertifikasi.

Guru dan dosen adalah komponen penting yang menentukan keberhasilan sistem pendidikan secara keseluruhan. Sebagaimana pernyataan Undang-Undang Republik Indonesia Nomor 14 Tahun 2005 tentang Guru dan Dosen. Pendidikan yang bermutu sangat tergantung pada kapasitas satuan-satuan pendidikan dalam mentransformasikan peserta didik untuk memperoleh nilai tambah, baik yang terkait dengan aspek olah pikir, rasa, hati, dan raganya. Dari sekian banyak komponen pendidikan, guru dan dosen merupakan faktor yang sangat penting dan strategis dalam usaha meningkatkan mutu pendidikan di setiap satuan pendidikan. Berapa pun besarnya investasi yang ditanamkan 
untuk memperbaiki mutu pendidikan, tanpa kehadiran guru dan dosen yang kompeten, profesional, bermartabat, dan sejahtera, dapat dipastikan tidak akan tercapai tujuan yang diharapkan.

Menurut Mulyasa (2009) guru merupakan titik sentral dari peningkatan kualitas pendidikan yang bertumpu pada kualitas proses belajar mengajar. Guru yang memiliki kompetensi tinggi akan menghasilkan proses dan hasil pendidikan yang berkualitas dalam rangka mewujudkan manusia Indonesia yang cerdas dan kompetitif.

Pendidikan berfungsi mengembangkan kemampuan dan membentuk watak serta peradaban bangsa yang bermartabat, sebagaimana tercantum dalam Undang-Undang Republik Indonesia Nomor 20 Tahun 2003 pasal 4 tentang sistem pendidikan nasional yaitu:

Pendidikan nasional berfungsi mengembangkan kemampuan dan membentuk watak serta peradaban bangsa yang bermartabat dalam rangka mencerdaskan kehidupan bangsa, bertujuan untuk berkembangnya potensi peserta didik agar menjadi manusia yang beriman dan bertaqwa kepada Tuhan Yang Maha Esa, berakhlak mulia, sehat, berilmu, cakap, kreatif, mandiri dan menjadi warga negara yang demokrasi serta bertanggung jawab.

Masyarakat Indonesia menuntut peningkatan dan perbaikan kualitas pendidikan karena pentingnya pendidikan. Jika pendidikan di Indonesia ingin maju maka para guru yang menjadi ujung tombaknya harus profesional baik dalam bidang keahliannya (kompetensi), dalam bidang pendampingan, dan dalam kehidupannya yang dapat dicontoh oleh siswa (Suparno, 2004). Upaya peningkatan tersebut harus dilakukan secara kontinyu yang salah satunya dapat dilakukan dengan peningkatan kualitas pendidik. Peningkatan kualitas pendidik dapat dilakukan dengan meningkatkan kompetensi yang dimilikinya serta diadakan uji sertifikasi sesuai dengan pekerjaan yang diembannya.

Menurut Sanaky (2004), sertifikasi guru merupakan kebijakan yang sangat strategis karena langkah dan tujuan melakukan sertifikasi guru untuk meningkatkan kualitas guru, meningkatkan kompetensinya, mengangkat harkat dan wibawa guru sehingga guru lebih dihargai dan untuk meningkatkan pendidikan di Indonesia. 
Pelaksanaan sertifikasi akan disertai dengan peningkatan penghargaan terhadap guru atau dosen yang telah lulus sertifikasi. Penghargaan ini antara lain berupa kenaikan tunjangan profesi ataupun peningkatan kesejahteraan lain. Meskipun demikian, hendaknya sertifikasi tidak hanya dipandang sebagai alat untuk memperoleh kenaikan tunjangan profesi dan peningkatan kesejahteraan semata.

Pelaksanaan sertifikasi harus dilakukan by process agar sertifikasi tersebut dapat menunjukkan kemampuan dan keterampilan guru dalam mengajar. Menurut Sanaky (2004) bagi para guru yang berasal dari fakultas keguruan sebelum diuji sertifikasi perlu disegarkan kembali pada aspek materi keilmuan, keterampilan dan strategi mengajar. Bagi para guru yang berasal dari non-kependidikan, sebelum uji kompetensi dan sertifikasi, perlu mengikuti latihan atau mengambil pendidikan profesi keguruan dengan bobot sejumlah 36-40 SKS. Jika proses tersebut dilaksanakan sistematis, terencana dan obyektif serta terhindar dari cara-cara instan, maka kualitas dan kompetensi guru dapat dipertangungjawabkan.

Kemungkinan yang terjadi adalah tidak sedikit dosen melakukan cara instan untuk dapat lulus uji sertifikasi. Tidak sedikit oknum dosen yang memanipulasi berkas kelengkapan penilaian sertifikasi untuk lolos uji sertifikasi dan memperoleh sertifikat pendidik. Demi terlaksananya sertifikasi "by procces" yang mampu meningkatkan kualitas dan kompetensi dosen yang pada akhirnya akan meningkatkan kualitas pendidikan di Indonesia, maka diperlukan komitmen dari berbagai pihak.

Program sertifikasi guru dan dosen dimandatasikan oleh Undang-Undang Republik Indonesia Nomor 14 Tahun 2005 tentang Guru dan Dosen. Program sertifikasi ini merupakan usaha untuk meningkatkan kualitas guru dan dosen serta meningkatkan kualitas sektor pendidikan secara keseluruhan. Darling-Hammond (1999) dan DarlingHammond, Berry, dan Thoreson (2001) membuktikan bahwa pencapaian nilai siswa dengan guru pengampu yang certified lebih tinggi dari pada nilai siswa dengan guru pengampu yang non-certified. Ini menunjukkan bahwa sertifikasi guru berpengaruh terhadap keberhasilan siswa dalam pencapaian nilai.

Goldhaber dan Brewer (2000) menemukan bahwa terdapat pengaruh positif signifikan sertifikasi guru terhadap keberhasilan siswa dalam pencapaian nilai untuk mata pelajaran Matematika. Myrberg dan Monica (2004) menyatakan bahwa sertifikasi guru berpengaruh terhadap kompetensi guru yang pada akhirnya mempengaruhi 
keberhasilan belajar siswa. Myrberg dan Monica (2004) melakukan penelitian pada sekolah swasta dan sekolah negeri di Swedia. Hasilnya bahwa pengaruh sertifikasi terhadap kompetensi guru sama kuatnya baik di sekolah swasta maupun di sekolah negeri.

Fahmi, Achmad, dan Arief (2011) mengaplikasikan dua teknik evaluasi yang berbeda yaitu Propensity Score Matching (PSM) dan Difference-in-Difference untuk mengevaluasi pengaruh sertifikasi. Teknik ini digunakan untuk mengestimasi perbedaan kinerja siswa (dilihat dari nilai ujian nasional) dikaitkan dengan sertifikasi. Hasil penelitian Fahmi et. al (2011) berseberangan dengan penelitian Darling-Hammond (1999), Goldhaber dan Brewer (2000) serta Myrberg dan Monica (2004). Hasil penelitian Fahmi et. al (2011) menunjukkan bahwa sertifikasi guru tidak memiliki pengaruh terhadap kesuksesan siswa.

Hal yang utama adalah terlaksananya sertifikasi yang mampu meningkatkan kualitas dan kompetensi dosen. Penyelenggaraan sertifikasi dosen ini pada akhirnya diharapkan akan memberikan sumbangsih penting dan positif berupa peningkatan kualitas lulusan suatu perguruan tinggi. Berdasarkan uraian sebelumnya, peneliti merasa perlu melakukan penelitian mengenai kompetensi dosen tersertifikasi menurut persepsi mahasiswa.

Penelitian ini dilakukan di Program Studi Pendidikan Akuntansi IKIP PGRI MADIUN. Penelitian bertujuan untuk mengetahui perbedaaan persepsi mahasiswa (berdasar angkatan) mengenai kompetensi dosen tersertifikasi. Menurut UndangUndang Republik Indonesia Nomor 14 Tahun 2005 pasal 1 ayat 10 kompetensi adalah seperangkat pengetahuan, keterampilan dan perilaku yang harus dimiliki, dihayati dan dikuasai oleh guru atau dosen dalam melaksanakan keprofesionalan. Kompetensi dosen sebagai aspek penilaian dalam program sertifikasi dosen terdiri atas empat (4) kompetensi yaitu:

1. Kompetensi pedagogik yaitu kemampuan merancang pembelajaran, kemampuan melaksanakan proses pembelajaran, kemampuan menilai proses dan hasil pembelajaran, dan kemampuan memanfaatkan hasil penelitian untuk meningkatkan kualitas pembelajaran (Mustiningsih dan Sunarni, 2009). Aspek yang dinilai dalam kompetensi pedagogik meliputi: 
a. Kesiapan dosen dalam memberikan kuliah dan/ atau praktek/ praktikum (Ped1).

b. Keteraturan dan ketertiban dosen dalam penyelenggaraan perkuliahan $(\operatorname{Ped} 2)$.

c. Kemampuan dosen untuk menghidupkan suasana kelas (Ped3).

d. Kejelasan penyampaian materi dan jawaban terhadap pertanyaan di kelas (Ped4).

e. Kemampuan dalam memanfaatkan media dan teknologi pembelajaran (Ped5).

f. Keanekaragaman cara pengukuran/ penilaian hasil belajar (Ped6).

g. Pemberian umpan balik terhadap tugas/penilaian (Ped7).

h. Kemampuan menyesuaikan materi ujian dan/ atau tugas dengan tujuan mata kuliah (Ped8).

i. Kesesuaian nilai yang diberikan dengan hasil belajar / memberikan nilai secara obyektif (Ped9).

2. Kompetensi profesional merupakan kemampuan penguasaan materi pembelajaran secara luas dan mendalam yang memungkinkannya membimbing peserta didik memenuhi standar kompetensi yang ditetapkan dalam standar pendidikan (Darmadi, 2010). Aspek yang dinilai dalam kompetensi profesional meliputi:

a. Kemampuan menjelaskan pokok bahasan/ topik secara tepat (Prof1).

b. Kemampuan memberi contoh relevan dari konsep yang diajarkan (Prof2).

c. Kemampuan menjelaskan keterkaitan bidang/ topik yang diajarkan dengan bidang/ topik lain (Prof3).

d. Kemampuan menjelaskan keterkaitan bidang/ topik yang diajarkan dengan konteks kehidupan (Prof4).

e. Penguasaan isu-isu mutakhir dalam bidang yang diajarkan / kemutakhiran bahan/ referensi kuliah (Prof5).

f. Penggunaan hasil-hasil penelitian untuk meningkatkan kualitas perkuliahan (Prof6).

g. Pelibatan mahasiswa dalam penelitian/ kajian dan atau pengembangan/ rekayasa/ desain yang dilakukan dosen (prof7). 
h. Kemampuan menggunakan beragam teknologi komunikasi (Prof8).

3. Kompetensi kepribadian adalah kemampuan kepribadian yang mantab, stabil, dewasa, arif dan berwibawa, menjadi teladan bagi peserta didik dan berakhlak mulia (Darmadi, 2010). Aspek yang dinilai dalam kompetensi kepribadian meliputi:

a. Kewibawaan sebagai pribadi dosen (Kepr1).

b. Kearifan dalam mengambil keputusan (Kepr2).

c. Kemampuan untuk menjadi contoh dalam bersikap dan berperilaku (Kepr3).

d. Satunya kata dan tindakan / keselarasan antara perkataan dan tindakan (Kepr4).

e. Kemampuan mengendalikan diri dalam berbagai situasi dan kondisi (Kepr5).

f. Adil dalam memperlakukan mahasiswa (Kepr6).

4. Kompetensi sosial adalah kemampuan pendidik sebagai bagian dari masyarakat untuk berkomunikasi dan bergaul secara efektif dengan peserta didik, sesama pendidik, tenaga kependidikan, orangtua/wali peserta didik dan masyarakat sekitar (Darmadi, 2010). Aspek yang dinilai dalam kompetensi sosial meliputi:

a. Kemampuan menyampaikan pendapat (Sos1).

b. Kemampuan menerima kritik, saran dan pendapat dari mahasiswa (Sos2).

c. Mengenal dengan baik mahasiswa yang mengikuti kuliahnya (Sos3).

d. Mudah bergaul di kalangan teman sejawat, karyawan, dan mahasiswa (Sos4).

e. Toleransi terhadap keberagaman mahasiswa (Sos5).

Pemilihan aspek-aspek yang dinilai untuk masing-masing kompetensi berdasarkan pada Buku Pedoman Sertifikasi Pendidik Untuk Dosen oleh Ditjen Dikti Kementerian Pendidikan dan Kebudayaan 2012.

Oleh karena penelitian ini bertujuan untuk mengetahui perbedaan persepsi mahasiswa mengenai kompetensi dosen tersertifikasi, maka hipotesis yang diajukan adalah:

H0: Tidak terdapat perbedaan persepsi mengenai kompetensi dosen tersertifikasi oleh mahasiswa tahun angkatan 2010, 2011, 2012 dan 2013. 
H1: Terdapat perbedaan persepsi mengenai kompetensi dosen tersertifikasi oleh mahasiswa tahun angkatan 2010, 2011, 2012 dan 2013.

\section{METODE}

Penelitian ini termasuk penelitian komparatif yang bertujuan untuk membandingkan perbedaan persepsi mahasiswa (berdasar angkatan) mengenai kompetensi dosen tersertifikasi. Populasi penelitian adalah seluruh mahasiswa Program Studi Pendidikan Akuntansi IKIP PGRI Madiun yang diampu atau dibimbing langsung oleh dosen Program Studi Pendidikan Akuntansi yang telah tersertifikasi sampai dengan periode 2013. Jumlah dosen Program Studi Pendidikan Akuntansi yang telah tersertifikasi sampai dengan periode 2013 adalah 4 orang Dosen. Jumlah populasi penelitian sebanyak 384 mahasiswa. Teknik pengambilan sampel yang digunakan adalah teknik proportional random sampling yang dari empat angkatan (2010, 2011, 2012, 2013) menghasilkan sampel 80 mahasiswa. Masing-masing angkatan adalah 20 orang mahasiswa yang akan memberikan persepsi/penilaiannya mengenai kompetensi dosen.

Definisi operasional variabel yang digunakan dalam penelitian disampaikan sebagai berikut.

\section{Persepsi Mahasiswa Mengenai Kompetensi Dosen Tersertifikasi}

Persepsi sebagai proses psikis untuk merespon, mengorganisasi, dan menerjemahkan obyek atau peristiwa yang selanjutnya memberikan arti dan makna terhadap lingkungan (Mustiningsih dan Sunarni, 2009). Sedangkan, menurut Wursanto (2005) persepsi adalah proses pemberian arti oleh seseorang terhadap lingkungan. Persepsi dibutuhkan untuk memberikan arti, makna dan penilaian terhadap sesuatu objek tertentu.

Kompetensi merupakan kebulatan penguasaan pengetahuan, keterampilan dan sikap yang ditampilkan melalui unjuk kerja yang diharapkan dapat dicapai seseorang setelah menyelesaikan program pendidikan. Kompetensi dosen yang dinilai dari persepsi mahasiswa meliputi kompetensi pedagogik, kompetensi profesional, kompetensi sosial dan kompetensi kepribadian (Hikmat, 2009). Kompetensi juga 
menunjuk pada tindakan rasional yang dapat mencapai tujuan-tujuannya secara memuaskan berdasar kondisi (prasyarat) yang ditetapkan (Makmun, 2002).

Data penelitian berupa data primer diperoleh dengan menggunakan instrument berupa questioner. Jenis questioner yang digunakan adalah questioner tertutup yaitu questioner yang menghendaki jawaban pendek dari responden atau jawabannya diberikan dengan membubuhkan tanda tertentu (Riyanto, 2001). Jika ditinjau dari jawaban yang diberikan oleh responden yang dalam penelitian ini adalah mahasiswa, questioner termasuk dalam jenis questioner tidak langsung. Menurut Arikunto (2006) questioner tidak langsung yaitu jika responden menjawab tentang orang lain. Mahasiswa diharapkan mau memberikan jawaban/ penilaian tentang dosen tersertifikasi karena mahasiswa tersebut tentunya memiliki persepsi tersendiri tentang kompetensi dosen tersebut. Questioner terdiri atas pertanyaan-pertanyaan tertutup dengan lima pilihan jawaban skor sebagai berikut:

\section{Tabel 1. Pilihan Jawaban Questioner}

\begin{tabular}{|c|l|}
\hline Skor & \multicolumn{1}{|c|}{ Keterangan } \\
\hline 5 & sangat baik \\
\hline 4 & Baik \\
\hline 3 & kurang baik \\
\hline 2 & tidak baik \\
\hline 1 & sangat tidak baik \\
\hline
\end{tabular}

Untuk memperoleh data yang akurat maka peneliti melakukan uji instruments yang meliputi uji reliabilitas dan validitas. Teknik analisis data yang digunakan adalah analisis varian satu jalan (one way ANOVA). Menurut Priyatno (2011) one way ANOVA adalah analisis yang digunakan untuk menguji perbedaan antara tiga atau lebih kelompok sampel bebas dengan satu jalan.

\section{HASIL DAN PEMBAHASAN}

Berikut merupakan tabel deskriptif statistik variabel persepsi mahasiswa mengenai kompetensi dosen tersertifikasi di Program Studi Pendidikan Akuntansi IKIP PGRI MADIUN.

Tabel 2. Deskriptif Statistik Persepsi Mahasiswa

\begin{tabular}{lllll}
\hline Tahun Angkatan & N & Mean & Minimum & Maximum \\
\hline 2010 & 20 & 102,80 & 60 & 140 \\
2011 & 20 & 91,05 & 49 & 130 \\
2012 & 20 & 95,65 & 57 & 136 \\
2013 & 20 & 83,20 & 47 & 134 \\
\hline
\end{tabular}


Berdasarkan tabel hasil deskriptif statistic di atas dapat diketahui bahwa dari mahasiswa keempat tahun angkatan yaitu tahun 2010, 2011, 2012, dan 2013 ternyata mahasiswa tahun angkatan 2010 memiliki persepsi paling baik tentang kompetensi dosen tersertifikasi. Ini terlihat dari nilai mean untuk persepsi mahasiswa tahun angkatan 2010 paling tinggi yaitu 102,8 dibanding dengan persepsi mahasiswa tahun angkatan sesudahnya. Hal tersebut dimungkinkan karena mahasiswa tahun angkatan 2010 telah lama mengenal dosen yang bersangkutan (yang dinilai kompetensinya) sehingga mereka memiliki persepsi yang paling baik mengenai kompetensi dosen tersertifikasi. Untuk persepsi mahasiswa tahun angkatan 2011 memiliki nilai mean 91,5 dengan nilai minimum persepsi 49 dan nilai maximum persepsi 130. Persepsi mahasiswa tahun angkatan 2012 tentang kompetensi dosen tersertifikasi memiliki nilai mean 95,65 dengan nilai minimum 57 dan nilai maximum 136. Dari keempat tahun angkatan, mahasiswa tahun angkatan 2013 memiliki nilai mean persepsi paling rendah yaitu 83,20 dengan nilai minimum 47 dan nilai maximum 134. Hal tersebut bisa dijelaskan bahwa mahasiswa tahun angkatan 2013 adalah mahasiswa semester pertama pada saat penelitian ini dilaksanakan. Karena masih baru dimungkinkan mahasiswa tahun angkatan 2013 belum begitu mengenal dosen yang bersangkutan sehingga mereka memiliki nilai persepsi yang paling rendah.

Selanjutnya analisis varian satu jalan (One Way ANOVA) dilakukan untuk membuktikan hipotesis yang diajukan dalam penelitian, yaitu untuk mengetahui perbedaan persepsi mahasiswa tahun angkatan 2010, 2011, 2012, dan 2013 mengenai kompetensi dosen tersertifikasi. Berikut disajikan tabel hasil pengujian One Way ANOVA.

Tabel 3. Hasil analisis One Way ANOVA

Persepsi Mahasiswa

\begin{tabular}{|l|r|r|r|r|r|}
\hline & \multicolumn{1}{|c|}{$\begin{array}{c}\text { Sum of } \\
\text { Squares }\end{array}$} & Df & Mean Square & F & Sig. \\
\hline Between Groups & 4055,650 & 3 & 1351,883 & 2,432 & 0,072 \\
Within Groups & 42245,900 & 76 & 555,867 & & \\
Total & 46301,550 & 79 & & & \\
\hline
\end{tabular}

Sumber: data olahan peneliti

Berdasarkan hasil analisis One Way ANOVA sebagaimana tersaji pada tabel 3 di atas, diketahui nilai $\mathrm{F}$ hitung sebesar 2, 432 dengan nilai signifikansi sebesar 0,072. Menurut Priyatno (2011) kriteria pengujian One Way ANOVA adalah: 
$\mathrm{H} 0$ diterima jika nilai $\mathrm{F}$ hitung $\leq \mathrm{F}$ tabel

$\mathrm{H} 0$ ditolak jika nilai $\mathrm{F}$ hitung $>\mathrm{F}$ tabel

Hasil untuk nilai $\mathrm{F}$ tabel dengan df $1=3$, dan df $2=76$ diperoleh nilai $\mathrm{F}$ tabel sebesar 2,725. Oleh karena nilai F hitung sebesar 2,432 lebih kecil dari nilai $F$ tabel $(2,725)$ maka H0 diterima. Tidak terdapat perbedaan persepsi mengenai kompetensi dosen tersertifikasi oleh mahasiswa tahun angkatan 2010, 2011, 2012 dan 2013. Begitu juga dengan nilai signifikansi sebesar 0,072 lebih kecil dari level of significant 0,05 yang turut mempertegas hasil pengujian bahwa tidak terdapat perbedaan persepsi mengenai kompetensi dosen tersertifikasi oleh mahasiswa tahun angkatan 2010, 2011, 2012 dan 2013. Meskipun dari hasil deskriptif statistik diketahui nilai mean untuk persepsi mahasiswa masing-masing tahun angkatan berbeda dimana mahasiswa tahun angkatan 2010 memiliki persepsi yang paling baik (dengan nilai mean paling tinggi) dan mahasiswa tahun angkatan 2013 memiliki persepsi paling rendah, namun secara keseluruhan, pengujian membuktikan tidak terdapat perbedaan persepsi mahasiswa tahun angkatan 2010, 2011, 2012, dan 2013 mengenai kompetensi dosen tersertifikasi di lingkup Program Studi Pendidikan Akuntansi IKIP PGRI MADIUN.

\section{SIMPULAN}

Berdasarkan hasil analisis maka dapat ditarik kesimpulan penelitian sebagai berikut: 1) mahasiswa tahun angkatan 2010 memiliki persepsi yang paling baik mengenai kompetensi dosen tersertifikasi. Hal ini dikarenakan mahasiswa tahun angkatan 2010 telah lama mengenal dosen yang bersangkutan (yang dinilai kompetensinya) sehingga mereka memiliki persepsi yang paling baik mengenai kompetensi dosen tersertifikasi. Selain itu karena kedekatan antara mahasiswa tahun angkatan 2010 dengan dosen yang bersangkutan serta akumulasi jumlah pertemuan baik berupa pembimbingan atau perkuliahan lebih banyak jika dibanding dengan mahasiswa tahun angkatan sesudahnya. Hal ini menjadikan mahasiswa memberikan penilaian/ persepsi yang baik terhadap aspek masing-masing kompetensi dosen yang meliputi kompetensi Pedagogik, kompetensi profesional, kompetensi kepribadian, dan kompetensi sosial. Jumlah nilai persepsi paling rendah diberikan oleh mahasiswa tahun angkatan 2013 yaitu mahasiswa semester pertama pada saat penelitian ini dilaksanakan. Ini dikarenakan mahasiswa tahun angkatan 2013 adalah mahasiswa baru yang belum 
begitu mengenal dosen yang bersangkutan. Selain itu juga dimungkinkan karena hubungan antara mahasiswa tahun angkatan 2013 dengan dosen bersangkutan masih dalam tahap penjajakan. 2) Hasil dari pengujian hipotesis dengan menggunakan analisis one way Anova diketahui bahwa tidak terdapat perbedaan persepsi mengenai kompetensi dosen tersertifikasi oleh mahasiwa tahun angkatan 2010, 2011, 2012, dan 2013. Jadi secara keseluruhan nilai persepsi yang diberikan mahasiswa masing-masing tahun angkatan mengenai kompetensi dosen tersertifikasi tidak ada perbedaan. Meskipun jika dilihat secara parsial melalui hasil deskriptif statistic berbeda namun perbedaan nilai persepsi ini masih pada kategori yang sama.

Berdasarkan pemaparan hasil penelitian, maka peneliti menyampaikan saran yang diharapkan akan bermanfaat diantaranya: untuk dosen hendaknya selalu berupaya meningkatkan kompetensi pedagogik, profesional, kepribadian, dan kompetensi sosial. Selain itu juga diharapkan dosen mampu membangun atmosfir akademik yang kondusif sehingga terbina suasana akrab antara mahasiswa dan dosen tanpa mengurangi kewibawaan dosen. Saran bagi penelitian berikutnya yang hendak meneliti kasus sejenis sebaiknya memperluas lingkup serta sampel penelitian yaitu tidak hanya sebatas pada mahasiswa satu lingkup program studi saja namun pada mahasiswa satu lingkup perguruan tinggi .

\section{DAFTAR RUJUKAN}

Arikunto, S. 2006. Prosedur Penelitian, Suatu Pendekatan Praktik. Jakarta: Rineka Cipta

Darling-Hammond, L. 1999. Teacher Quality and Student Achievement: A review of state policy evidence. Seattle, WA: Center for the Study of Teaching and Policy,University of Washington.

Darling-Hammond, L. Berry, B. dan Thoreson, A. 2001. Does Teacher Certification Matter? Evaluating the Evidence. Educational Policy Analysis, 23(1) pp 57-77.

Darmadi, H. 2010. Kemampuan Dasar Mengajar, Landasan dan Konsep Implementasi. Bandung: Alfabeta.

Direktorat Jenderal Pendidikan Tinggi Kementerian Pendidikan dan Kebudayaan. 2012. Buku Pedoman Sertifikasi Pendidik Untuk Dosen (Buku 2) Penilaian Portofolio.

Fahmi, M., Achmad M., dan Arief A. Y. 2011. Teacher Certification in Indonesia: A Confusion of Means and Ends. Center for Economics and Development Studies $(C E D S)$, Padjajaran University. 
Goldhaber, D, and Brewer, D. 2000. "Does Teacher Certification Matter? High School Teacher Certification Status and Student Achievement." Educational Evaluation and Policy Analysis, 22(2), pp.129-145.

Hikmat. 2009. Manajemen Pendidikan. Bandung: Pustaka Setia.

Makmun, Abin S. 2002. Psikologi Kependidikan Perangkat Sistem Pengajaran Modul. Bandung: Remaja rosdakarya.

Mulyasa. 2009. Standar Kompetensi dan Sertifikasi Guru. Bandung: Remaja Rosdakarya.

Mustiningsih dan Sunarni. 2009. Persepsi Dosen Terhadap Program Sertifikasi Kaitannya dengan Profesionalisme. Jurnal Penelitian Kependidikan, tahun 19, no 2, Oktober, pp 99-107.

Myrberg, E. dan Monica R .2004. The Impact of Teacher Competence in Public and Independent Schools in Sweden. From:http//www.google.com akses 16 Agustus 2012.

Priyatno, Dwi. 2011. SPSS: Analisis Statistik Data. Yogyakarta: MediaKom.

Riyanto, Y. 2001. Metodologi Penelitian Pendidikan. Surabaya: SIC.

Sanaky, Hujair A.H. 2004. Kompetensi dan Sertifikasi Guru "Sebuah Pemikiran" . From:http//www.kompas.com akses 16 Agustus 2012.

-----------, 2004. Tantangan Pendidikan Islam di Era Reformasi (Pergeseraan Paradigma Pendidikan Islam Indonesia di Era Reformasi) Jurnal Studi Islam MUKADIMMAH, Kopertis Wilayah III dan PTAIS DIY, no 16 tahun X / 2004, ISSN: 0853-6759, Yogyakarta.

Suparno, P. 2004. Guru Demokratis di Era Reformasi. Jakarta: Grasindo.

Undang-Undang Republik Indonesia Nomor 20 Tahun 2003 tentang Sistem Pendidikan Nasional.

Undang-Undang Republik Indonesia Nomor 14 Tahun 2005 tentang Guru dan Dosen.

Wursanto, I. G .2005. Dasar-Dasar Ilmu Organisasi. Yogyakarta: Andi. 